\title{
Representation of Woman Existentialist Reflected from Archetypal Image Analysis in The Chrysanthemums Story
}

\author{
Desria Natalia Sirait ${ }^{1}$, Tomi Arianto ${ }^{2}$ \\ sirait.natalia09@gmail.com¹, tomy2088.ta@gmail.com² \\ 1,2Social Sciences and Humanities, Putera Batam University, Indonesia
}

Received: 13 November 2020 Accepted: 23 November 2020

DOI: $10.24256 /$ ideas.v8i2.1678

\begin{abstract}
This study aims at analyzing the representation of women's existence through the archetypal image in the chrysanthemum story. This study uses Carl Jung's archetypal image theory which is supported by Simone de Beauvoir's theoretical concepts. This research is focused on analyzing archetypal image. This story is revealed by classifying symbol, persona, anima and animus archetypal, and self-archetypal. Meanwhile, further analysis of the archetypal symbol is then criticized using the concept of the woman existentialist Simone de Beauvoir. This study uses a qualitative research method in which all data sources are taken from the short story. The results showed that there are four symbols of archetypal, personal archetypal, opposing points of view of anima and animus archetypal, and how to control self-archetypal. From all of these classifications, it is concluded that the representation of an existentialist woman is reflected through the main character named Elisa, including daring to go against the rules, being able to make their own decisions and being a woman who can stand alone.
\end{abstract}

Keywords: Archetypal; Symbol; Woman Existentialist 
Representation of Woman Existentialist Reflected from Archetypal Image Analysis in "The Chrysanthemums" Story

\section{Introduction}

The form of writing that exists in a media, both today's printed media and ancient stone media, is a depiction of literary works that is used as an indication of what happened in ancient times. Writings can be found through the existing cave walls and have their own meaning from the process that literary works occur and carry out development until now (Israel, 2020). To find out, we need to explore what literary works are for the purpose of providing knowledge to the recipient of information about some real facts (Koop et al., 2019). The arrangement of words will become signs and even symbols so that in the human mind they can digest these signs. To generate or initiate communication this communication can be done either through oral or written (Domagala and Podwleska, 2019). Taum (1997) described that ontologically (meaning of word based on the essence) that literature word can defined (a) literature is imaginative works or fiction; (b) literature is beautiful and useful language for other things and (c) literature is language text manipulated by the author to give an effects in its applications (Taum, 1997, pg.13)

In the literature there is the study of psychoanalysis, this psychoanalysis can be seen from the depiction of the character of personalities in the story. Psychoanalysis of characters can be found through depictions of daily life in stories, so the aim of this study is to analyze how the Archetypal image in "The Chrysanthemums" by John Steinbeck can occur. Short story "The Chrysanthemums" is an American classic in 1902 set in the Salinas Valley, California. "The Chrysanthemums" was published in 1937 by Harper's magazine, America. Sigmund Freud describes that the psychoanalytic approach illustrates that the need based on imagination for the pleasure principle, such as if we are hungry, our imagination describes food and our goal is to eat so we don't feel hungry, this explains that what the character thinks will be done to satisfy desire character itself.

According to Freud (1991) and Dolcos et al. (2020) the conscious mind is aware of the present perceptions, memories, thoughts, and feelings. It exists as the tip of the iceberg. Under this conscious mind, a preconscious mind carries the available memory. From this preconscious mind, a person can retrieve memories into the conscious mind. This psychoanalytic approach was developed by Freud to examine the unconscious conditions of the characters in a story to be examined. From this research, it can be concluded whether the characters in the story are completely controlled by internal factors or external factors. In image-archetype analysis Jung (2013) defined the person into 
an arbitrary collective physical form that exists due to the adaptation of a new society in an individual formed due to a process that is painstakingly difficult to go through.

Archetypal image analysis is containing elements of anima and archetypal animus. It relates to the treatment of women who discusses how someone has opposite traits. Resistance from a woman who has a masculine attitude makes Elisa determine her own rights and how Elisa makes decisions without needing other people's opinions. "To be feminine is to show one-self as weak, futile, passive, and docile. The girl is supposed not only to primp and dress herself up but also to repress her spontaneity and substitute for it the grace and charm she has been taught by her elder sisters. Any self-assertion will take away from her femininity and her seductiveness." (De Beauvoir, 1949) where women are not only dressed up and have no purpose. Women are demanded to be independent and able to stand on their own so as to erase the view of society that views women as only the weak (Duan, 2020).

In this short story, there are a lot of contradictions by Elisa to prove that women can also do what men can do. Gardening is more synonymous with men where in the story Elisa is the one who does gardening and she uses gardening equipment such as black hats, scissors, aprons, and gloves, and this shows the side of men in which men are used to doing things the. Elisa spent much of her time in her chrysanthemums garden caring for the flowers just like a mother caring for her child. In the story Elisa also shows her feminine side where she treats all flowers very carefully and all flowers flourish and she kills all pests before attacking the plant. Many people underestimate Elisa because they always look like men and Elisa's husband never cares about what Elisa is doing while making Elisa happy.

There are some researchers that had conducted this research, such as the first researcher Eko Hardanto, M.Natsir(2019)they have analyzed An Analysis of Smeagol's Character Influenced by The One Ring In Lord of The Rings: Return of The King Film Using Jung Archetypes. In their article they have discussed about the Hobbits and friends to save the Middle Earth. The main objective of this research is to explore the archetypes that exist in Smeagol and the role of one ring that is able to influence his personality. This study uses twelve archetype formulas, five of which are in Smeagol and one archetype is in one ring. Further analysis was carried out by Abitha \& Paul, (2016) entitled A study on the popularity of archetypal theory. This research discusses the relationship between the vampire novel and the basic theory, which is the change in vampire that occurs from 
Representation of Woman Existentialist Reflected from Archetypal Image Analysis in "The Chrysanthemums" Story

sympathetic vampires and old vampires. This research focuses the old vampires as evil vampires and they are dangerous like demons through the archetype of vampires thinking. The opposite of old vampires and very nearly invisible to the naked eye because the new vampires in their sympathetic vampires are more subtitle.

This research describes how the shape of anima and animus are depicted through the characters of Elisa and Henry. The portrayal of an archetypal image of anima through the character Elisa, which involves the role of women's existence and shows a woman who has a masculine side. This discussion of women's existence aims to analyze deeply how Elisa's character becomes a strong woman and is able to stand alone. Apart from the side of the women's existence, the depiction of the archetypal pattern, image analysis also helps in finding hidden meanings through symbols and personal archetypal. To seek a more in-depth analysis of this analysis, this research is guided by two research questions: (1) what are the forms of archetypal image analysis in The Chrysanthemums story? And (2) how do you describe the main characters through the side of women's existence in The Chrysanthemums story?

\section{Method}

This research analyzes the Archetypal Image using Jung's theory of the short story "The Chrysanthemums" by John Steinbeck. This study discusses the description given by two main characters that describe the Archetypal elements in the story so that it is very good for in-depth analysis. This research uses qualitative methods; this qualitative research is a type of research in which there are social and cultural elements in the form of literary works so it is very good to use qualitative research methods. The data collected comes from the research object, which becomes the object of this research is a short story entitled "The Chrysanthemums" by John Steinbeck. According to Creswell (2014), data analysis technique is the process of compiling sequence data by classifying it into pattern units, categories, and basic descriptions. The technique used in this research is data analysis in stories. This study was conducted to analyze the content using the Image-Archetypal theory in literature by Jung to determine the personality aspects of the characters. Data obtained from the object of research in the form of words, sentences and others to explain how important data is in research. 


\section{Results}

Archetypal Image

1. Symbols

1.1 Water

"Elisa watched them for a moment and then went back to her work. She was thirty-five. Her face was lean and strong and her eyes were as clear as water." (Steinbeck, 1937)

From the analysis of the first symbol, namely "Water" water often appears several times in the story because water is an important element in the story. Analysis of the symbol "Water" in the story symbolizes "fertility, growth, and purity" from the two quotes above that they need water to bathe and use water to water their plants. The meaning of water in the story represents the "fertility, growth, and purity" they get after they water their plants with water. Furthermore, the purity that is reflected in Elisa's eyes symbolizes Elisa, a strong and much energized person. In the Imagearchetype, Water analysis is symbolized as the source of life

\subsection{The Chrysanthemum}

She took off a glove and put her strong fingers down into the forest of new green chrysanthemum sprouts that were growing around the old roots. She spread the leaves and looked down among the close-growing stems. No aphids were there, no sow bugs or snails (Steinbeck, 1937)

The next analysis is the chrysanthemum flower which is the title in this story so that it becomes important and contains several meanings from this one symbol. The meaning of the symbol The first chrysanthemum symbolizes "child". In this story Elisa and Henry Allan cannot have children because of impotence. From the quote above, it can be concluded that the meaning of the chrysanthemum is a child that the family has been waiting for a long time. The quote above states that Elisa doesn't want any pests in her chrysanthemum plants so that her chrysanthemums don't die. This shows that Elisa depicts the figure of a mother who cares for her child wholeheartedly who doesn't want anything untoward to happen to her child. Besides symbolizing a chrysanthemum child, it also has another meaning, namely feminism and sex. The chrysanthemum flower symbolizes 
Representation of Woman Existentialist Reflected from Archetypal Image Analysis in "The Chrysanthemums" Story

the female side of Elisa who is difficult to express herself because in the story they have a house that is far away from their neighbors.

\subsection{Sun}

On the foothill ranches across the Salinas River, the yellow stubble fields seemed to be bathed in pale cold sunshine, but there was no sunshine in the valley now in December. The thick willow scrub along the river flamed with sharp and positive yellow leaves(Steinbeck, 1937)

The next analysis is the sun, the symbol of "SUN" does not only have meaning about light. The sun is a natural image which has the meaning of "energy" in the story, which begins with the rising of the sun's rays, but it is not so clear because it has entered the month of December where snow will fall. The sun in Archetypal analysis means "Energy", which is when Elisa wakes up early and gets sunlight, the sun gives Elisa new energy and new enthusiasm. So, in the analysis of Image- Archetypal Sun is defined as new energy that we will get every day.

\subsection{Colors}

\subsubsection{Green}

The strangers were getting into their Ford coupe. She took off a glove and put her strong fingers down into the forest of new green chrysanthemum sprouts that were growing around the old roots (Steinbeck, 1937)

Next the first color analysis is green. In the story there is a chrysanthemum plantation that stretches out in green and looks very beautiful. In the archetype analysis, the green color depicts the "fertility" of the chrysanthemum growth treated by Elisa, which thrives and spreads widely. The meaning of green which symbolizes fertility proves that the land in Salinas where Elisa planted chrysanthemums is fertile soil, apart from green fertility, it also cooperates with the meaning of growth which describes the figure of Elisa who is so patient and painstaking in caring for her plants so that her plants are far from pests and thrive In the land of Salinas.

\subsubsection{White}


Behind her stood the neat white farm house with red geraniums close-banked around it as high as the windows. It was a hard-swept looking little house, with hard-polished windows, and a clean mud-mat on the front steps. (Steinbeck, 1937)

The next color in archetype analysis is white. White color has the meaning of "honesty and purity" so that white symbolizes purity. In the view of the people, the white house looks big, neat, big, and beautiful. In the story of the chrysanthemum the houses of the residents there are neatly arranged and identical to the flowers that are always in front of the residents' houses. The houses at the foot of the Salinas Mountain are neatly painted with white house paint which symbolizes the purity and honesty of the place because its residents are very far from neighboring houses. Honesty is reflected through the friendly attitude of the residents because the population is small and exchanges greetings.

2. Personal Archetypal

Personal factors have an important role in a story, personal depiction is described through the character's personality in a story. This personal depiction shows how the character's attitude is with other characters and how he accentuates himself using his personal traits. The main character played by Elisa Allen has a good personality with a hard-working attitude, has a critical mind, and doesn't want to be underestimated by other characters so that Elisa becomes the most prominent character in the Chrysanthemum story. There are many personal attitude changes that Elisa did in the chrysanthemum story that made Elisa a character who has a personal attitude that is difficult to define as a personal image.

She looked down toward the men by the tractor shed now and then. Her face was eager and mature and handsome; even her work with the scissors was over-eager, over-powerful. The chrysanthemum stems seemed too small and easy for her energy (Steinbeck, 1937)

From the quote above, it describes Elisa's personal character who has critical thinking towards new people who come to their interests. Elisa watched the gesture of a man in suits talking to her husband Henry Allen. Elisa herself doesn't know why she has a high ego about how other people 
Representation of Woman Existentialist Reflected from Archetypal Image Analysis in "The Chrysanthemums" Story

see her so she misunderstands other people's views on Elisa. The quotation below shows that others thought that Elisa Allen was a great and energetic woman

He leaned confidentially over the fence. "Maybe you noticed the writing on my wagon. I mend pots and sharpen knives and scissors. You got any of them things to do?"

"Oh, no," she said quickly. "Nothing like that." Her eyes hardened with resistance (Steinbeck, 1937)

The next personal character that Elisa shows is a personal character who has critical and selfish thoughts like she doesn't need anyone else. This personal depiction is seen when a Tinker comes to her house to repair used pans and pans and intends to ask Elisa for a job but Elisa arrogantly replies that she doesn't need anyone else to help her cultivate her large chrysanthemum garden because she knows she and her husband can do everything. After Tinker returned from Elisa's house, on the way Elisa threw away Elisa's chrysanthemum with her annoyance when Tinker imagined Elisa's refusal to her. Of all the personal attitudes that Elisa does have the meaning of describing her own pattern in shaping and describing Elisa's character in the story so that Elisa becomes a complex personal character to understand.

3. Anima and Animus Archetypal

Anima and Animus Archetypal have contradictory meanings. According to Jung, these two aspects are a picture of the unconscious within oneself which will later erase one's identity so that the real situation will turn upside down. The difference between these two archetypes of collective unconsciousness makes the character have less clear goals which are influenced by unconscious conditions when the character experiences several influences such as environmental influences, economic influences, family influences, and so on. "The soul of every man has an inner feminine aspect (which he called "anima") and that the soul of every woman has an inner masculine aspect ("animus")" (Jung, 2013)

Anima is a depiction of the male side that has a feminine aspect, which in the real world is that women's duties are only done by women but because of the conscious nature at work and environmental factors that make anima appear unconsciously. Anima factor occurs in the character of 
Elisa's husband, henry Allen, where he understands his wife's stubborn nature but because of his affection for Elisa he wants to do some work that is supposed to be for women

"Elisa started at the sound of her husband's voice. He had come near quietly, and he leaned over the wire fence that protected her flower garden from cattle and dogs and chickens" (Steinbeck, 1937)

From the above quote Henry Allen her husband came with the intention of helping her tidy up her chrysanthemum garden, which is where the woman's job is to care for flowers. Flower symbolizes woman, so when Henry keeps flowers from chickens and other pests, it is a form of anima which shows the feminine aspect of Henry which is influenced by environmental factors. Henry, her husband, did all of this to mean that Elisa would not feel alone in taking care of the vast chrysanthemum garden.

In addition to the anima attitude described by men, the next is the Archetypal Animus depiction which means that women have an inner masculine aspect. The nature of the animus is what makes Elisa the main character with the character of the animus that stands out in the chrysanthemum story. Next is the form of treatment done by Elisa's character which originates because of Elisa's unconsciousness of what she does everyday in the story. Changing a woman's character to a masculine aspect requires a lot of courage so that it is difficult to restore the perspective of society towards a woman who has the most prominent attitude in a family.

"Her figure looked blocked and heavy in her gardening costume, a man's black hat pulled low down over her eyes, clod-hopper shoes, a figured print dress almost completely covered by a big corduroy apron with four big pockets to hold the snips, the trowel and scratcher, the seeds and the knife she worked with" (Steinbeck, 1937)

From the quote above, it seems that the animus from Elisa is where she replaces her husband Henry. The farm job by holding a shovel and wearing a hat is a symbol of Elisa's masculine prowess which makes Elisa look like a man. Another animus symbol occurs in the story when Elisa does all the work, and she also doesn't need the help of a tinker, a pot filler, even she doesn't need help because she shows that she is an independent woman and a woman who doesn't care what other people say. 
Representation of Woman Existentialist Reflected from Archetypal Image Analysis in "The Chrysanthemums" Story

4. Self-Archetypal

Self-Archetypal is the most prominent aspect of Jung's theory, where self-archetypal is a way of self-control with the subconscious part of a human being which is a very important archetypal pattern in the discussion of archetypal. The formulation of these archetypes plays a big role in dealing with characters who have a big influence to help someone explore their potential to become self-archetypes who have high potential in maintaining self-esteem.

After a while she began to dress, slowly. She put on her newest underclothing and her nicest stockings and the dress which was the symbol of her prettiness. She worked carefully on her hair, penciled her eyebrows and rouged her lips. (Steinbeck, 1937)

Self-Archetypal shows Elisa's attitude, if at the beginning of the story she is a tough, hard-working, and selfish person so that Elisa's neighbors think She is someone who is difficult to recognize. But in the case of Elisa is a kind person and has a fragile heart because it is influenced by several aspects of their home life. The quote above shows the feminine side of Elisa, which is depicted as a woman wearing gardening clothes and boots with shovels. The quote above makes Elisa look feminine when Henry takes Elisa out for dinner and Elisa wears a very nice dress and she dresses up so as not to disappoint her husband at the dinner.

\section{Woman Existentialist}

The research focuses on the main character of a woman who has a masculine soul named Elisa in the story The Chrysanthemums. Existentialist women's representation is reflected in the main character named Elisa, including the courage to go against the rules, able to make their own decisions and become a woman who can stand alone. Elisa's ability to take on more roles in her life in the story makes her husband unable to do much. The existence of women is reflected in the character Elisa who does not think about what other people say, so what she thinks is all right. Several quotes in the story refer to Elisa's attitude which has a more prominent masculine side.

"Her figure looked blocked and heavy in her gardening costume, a man's black hat pulled low down over her eyes ..."(Steinbeck, 1937) 
"A figured print dress is almost completely covered by a big corduroy apron with four big pockets to hold the snips, the trowel, and scratcher, the seeds and the knife she worked with ..."(Steinbeck, 1937)

From the above quote Elisa as if incarnated like a man, it can be seen with Elisa using 'man's black hat'. 'Man's black hat' seems like Elisa accentuates her maleness. Elisa is deemed to have been out of what other women usually use and this causes a symbol that even women can be like men. The snips, the trowel, the scratcher, the seeds and the knife are tools commonly used for gardening and are synonymous with men. All of that refers to the male side and Elisa seems to be out of the "boundary" of women in general, besides that it shows that women can do what men do.

\section{Discussion}

This study discusses how women's existence is illustrated through the Archetypal image in Jung's theory. Further analysis is also found in articles from Eko Hardanto, M.Natsir, (2019)regarding archetypes the one ring and also Abitha \& Paul(2016)which discusses the popularity of archetypal. From the two previous studies, there are some facts that were not found by previous researchers. The first work from Eko Hardanto, M.Natsir(2019)which specifically discusses the part of the collective unconscious with the twelve types of archetypes. This study uses data contained in Lord of the Rings: Film Return of the King. From this study, we get a research result that focuses on how One Ring affects Smeagol's personality. Psychological tests have also been used by previous researchers to look for types containing the ego, personal unconscious, and collective unconscious.

The same is the case with the second research by Abitha \& Paul(2016)which discusses how Carl Gustav Jung first applied the archetypal theory to analyze stories that contain elements of imagination and mythic. This study discusses the archetypal differences that occur between the old vampire and the new vampire. This research uses that the old vampire in the story is told to be more sinister and frightening to humans and the new vampire in the developing story is the opposite of the old vampires which makes the archetypal analysis deeper.

After discussing previous research studies, the current research will show some differences with previous studies. The first is how to connect the archetypal image to women's existence so that it produces an interesting mix of analyzes. Analysis of women's existence using De Beauvoir(1949) theory show in current 
Representation of Woman Existentialist Reflected from Archetypal Image Analysis in "The Chrysanthemums" Story

research that Elisa is a woman who can make her own decisions without requiring advice from her surroundings. Women's existence in an archetypal image is illustrated through the Animus that occurs in Elisa, a woman who has masculine characteristics. The description of the archetypal image of the animus, according to Jung, is innate from oneself which is influenced by the environment and external pressure and this occurs naturally.

Second differences contained in the current research are the analysis of symbols in archetypal images that occur in the story. Analyses of symbols in stories have different meanings even hidden meanings so that they cannot be interpreted in a dictionary meaning. In addition to symbols, this study discusses the personal archetypal image which includes anima and animus archetypal image, in this study, the opposite side occurs naturally due to several factors. The last one is research on self-archetypal image which is the most important archetypal image in Jung's theory, in self-archetypal all the personality of the character will be clearly depicted if further analyzed using self-archetypal image. So, from the results of previous studies with current research there are several differences that have not been discussed in previous studies.

In this research, the researcher wants to analyze and discuss the main characters, namely Henry and Elisa Allen, who are the main focus in the discussion types of Archetypal that the researcher analyzes are symbols, Archetypal personal, Archetypal self, and Archetypal anima/animus. In first archetypal research regarding the symbols contained in Archetypal types based on Jung, there are several symbols in the chrysanthemum story, the first analysis of the Archetypal symbols consisting of water, sun, color, and circle symbols.

\section{Archetypal Image}

1. Symbol

In the water symbol, the researchers found that water plays an important role in the story because water is used as a source of fertility, growth, and purity. Elisa watered the crops every day using water and fed their livestock with water and water as their source of life. Besides the water symbol, there is a sun symbol which has a meaning as energy. The energy they get from the sunlight in the morning gives new enthusiasm for them to care for their plants and start their activities. The next symbol is the color, the colors contained in the chrysanthemum story are green and white, which means the green color is fertility and coolness. White color means purity and honesty where the average house there has a white color. 
The circle symbol symbolizes a problem that comes to Elisa when other people see Elisa as a selfish woman because almost all of Elisa's household and farm work is managing her so that neighbors who see her husband like Henry do not play much role in their household. The problem first occurred when Elisa was not happy to see her husband and a meat company expert who came to offer cooperation, the problem continued when a tinker to fill the pot came to offer a job where Elisa was annoyed because Tinker thought that Elisa was unable to manage their vast plantation so that need an assistant.

\section{Personal Archetypal}

Personal Archetypal analysis was then found in the character Elisa who has an important role in the story. Elisa's personal character description shows that Elisa is a hard worker and an independent woman and she is selfish because she thinks that she can do all the work without needing outside help. Besides that, Elisa's personal Archetypal describes that Elisa is a shop that has critical thinking because she can't accept things easily. The next aspect regarding Anima and Animus Archetypal in the chrysanthemum story is due to the reversal that occurs which is influenced by the subconscious which is suppressed by several factors that make a person do something because it has been influenced by his subconscious.

\section{Anima and Animus Archetypal}

Anima occurs in Henry's character who does work to care for flowers so that Anima is reflected in the nature of Henry being done because of internal factors where he wants to appear to support Elisa's work. The reverse side occurs, namely the Archetypal animus aspect performed by Elisa's character, seen when Elisa does all the work which sometimes she doesn't allow Henry to do. Elisha also uses gardening tools like a man, such as hats, shovels and others. This shows the Archetypal animus performed by a woman who has a masculine side to appear dignified and appreciated.

\section{Self-Archetypal}

The final analysis of the very important self-Archetypal from Jung's theory which states that all treatment of these traits comes from oneself and sometimes is carried out consciously and unconsciously. Like what Elisa did to Tinker when Tinker praised Elisa's neat plantation but behind it 
Representation of Woman Existentialist Reflected from Archetypal Image Analysis in "The Chrysanthemums" Story

she had a goal so that she was given a job, but Elisa didn't think about it so Elisa's character showed that Elisa's self was good but Selfish Archetypal.

\section{Woman Existentialist}

Representation of existentialist women reflected in the main character in The Chrysanthemums story Elisha's struggle against the opinions of others. Elisa represents a woman who is strong and brave in how she manages her vast plantation using shovels and other tools. Elisa's daily life makes her so tough that even foreigners who have just visited her farm feel reluctant to Elisa. New people's aversion to Elisa is often misunderstood, apart from the masculine side that Elisa has, Elisa is also a person who has critical thinking. This makes the representation of existentialist even stronger to be proven through the depiction of Elisa's character.

\section{Conclusion}

The research focuses on archetypal image and existentialist representation of women reflected in the main character named Elisa. The first depiction of archetypes uses symbols to look for certain meanings; the first symbol is water which depicts fertility, growth, and purity. Besides the water symbol, the next symbol is the sun which symbolizes energy besides the sun. In addition to symbols, archetypal personal also imagines how the characters in the story play a role, besides archetypal personal, there are also archetypal anima and animus which provide an inverse comparison between anima and animus, anima describes the male side which has a feminine aspect and the animus describes the opposite of the anima side, namely women which has a masculine aspect. The most important aspect of Archetypal is self- Archetypal which shows how the character actually plays a role in the story to have a big influence to help someone explore their potential to become self-archetypes who have high potential in maintaining self-esteem.

After analyzing how the archetypal image that occurs in the story through various things then connects the archetypal image with the representation of existentialist women reflected in the main character in The Chrysanthemums story. Elisha's struggle against the opinions of others regarding the nature that he does which is reflected in his daily activities makes Elisa a strong person. Elisa dared to make decisions on her own without having to negotiate with others while this was true. Existentialist representation of women allows Elisa to accentuate her 
masculine side that she doesn't want to be underestimated because she is a woman.

From all the discussions that have been discussed in this study, the researcher provides suggestions to every reader those women who are meant to be second sex does not mean that women have a small scope for expression. Women who have intellectual value are women who are able to highlight themselves with their abilities. In The Chrysanthemums story, the main character Elisa has extraordinary independence that is able to manage their vast plantation without paying attention to the words of others who do not develop. Therefore all women have the right to express themselves through images that come naturally and instinctively. Women as second sex are not there to be left behind,women have the same ability as men to express themselves.

\section{Acknowledgement}

First of all praise and worship to Allah for blessing me. Many thanks and acknowledgement goes to the entire first my parents, my friends, English teachers department, head of Social Sciences and Humanities, and PuteraBatam University.

\section{References}

Abitha, K., \& Paul, X. J. (2016). A study on the popularity of archetypal theory. Language in India, 16(11), 12-24.

Creswell, J. W. (2014). Research Design (V. Knight (ed.); 4th ed.). Sage Publications.

De Beauvoir, S. (1949). The Second Sex. In J. Thurman (Ed.), Vintage Books Edition: Vol. II (1st ed.). Vintage Books.

Duan, Z. (2020). An Interpretation of Sarah's Madness in The French Lieutenant's Woman from the Perspective of Michel Foucault's Theories about Madness. Journal of Humanities Insights, 4(03), 136-139.

Dolcos, F., Katsumi, Y., Moore, M., Berggren, N., de Gelder, B., Derakshan, N., ... \& Pegna, A. J. (2020). Neural correlates of emotion-attention interactions: From perception, learning, and memory to social cognition, individual differences, and training interventions. Neuroscience \& Biobehavioral Reviews, 108, 559-601.

Domagała-Zyśk, E., \& Podlewska, A. (2019). Strategies of oral communication of deaf and hard-of-hearing (D/HH) non-native English users. European Journal of Special Needs Education, 34(2), 156-171.

Eko Hardanto, M.Natsir, S. D. K. (2019). An Analysis of Smeagol's Character Influenced by The One Ring In Lord of The Rings: Return of The King Film Using Jung Archetypes. Jurnal Ilmu Budaya, 3(1), 106-120.

Freud, S. (1991). New Introductory Lectures on Psychoanalysis (J. Strachey (ed.)). Penguin Books. 
Desria Natalia Sirait, Tomi Arianto

Representation of Woman Existentialist Reflected from Archetypal Image Analysis in "The Chrysanthemums" Story

Koop, S. H. A., Van Dorssen, A. J., \& Brouwer, S. (2019). Enhancing domestic water conservation behaviour: A review of empirical studies on influencing tactics. Journal of environmental management, 247, 867-876.

Israel, T. (2020). Navigating Autonomy: A Mid-Career Reflection on Life in Academia. Women \& Therapy, 43(1-2), 170-181.

Jung, C. G. (2013). Essays on the psychology of the unconscious. Cogito-Center.

Masruddin, M. (2018). Lessons in Old Man and The Sea. IDEAS: Journal on English Language Teaching and Learning, Linguistics and Literature, 1(1). doi:https://doi.org/10.24256/ideas.v1i1.126.

Situmorang, F., \& Handayani, N. (2020). Illocutionary Act in Anger Management Movie. IDEAS: Journal on English Language Teaching and Learning, Linguistics and Literature, 8(1), 363 - 372. doi:https://doi.org/10.24256/ideas.v8i1.1424

Steinbeck, J. (1937). the_chrysanthemums_by_john_steinbeck (1st ed.). Magazine, herpers.

Taum, Y. Y. (1997). Pengantar Teori Sastra. In international conference on language: Vol. 11 .

Yusuf, F., \& Susilo, M. (2020). Existentialist Feminism of Woman's Struggle in Cigarette Girl Novel. IDEAS: Journal on English Language Teaching and Learning, Linguistics and Literature, 8(1).

doi:https://doi.org/10.24256/ideas.v8i1.1275 